\title{
Oxidored-nitro domain-containing protein 1 expression is associated with the progression of hepatocellular carcinoma
}

\author{
DENG-QING LI ${ }^{1}$, MING QIU $^{1}$, XIN-MIN NIE ${ }^{2}$, RONG GUI $^{2}$ and MIN-ZHU HUANG ${ }^{3}$ \\ ${ }^{1}$ Department of Laboratory Medicine, Xiangya Medical School; \\ ${ }^{2}$ Clinical Laboratory Centre of The Third Xiangya Hospital, Central South University, Changsha, Hunan 410013; \\ ${ }^{3}$ Public Health School of Central South University, Changsha, Hunan 410078, P.R. China
}

Received February 14, 2015; Accepted March 4, 2016

DOI: $10.3892 / 01.2016 .4362$

\begin{abstract}
Hepatocarcinogenesis is a stepwise process during which multiple genes are altered. Understanding the molecular mechanisms that induce hepatocarcinogenesis may improve the screening, prevention and treatment of patients with hepatocellular carcinoma (HCC). In recent years, the oxidored-nitro domain-containing protein 1 (NOR1) gene has been identified to have an important role in the development of $\mathrm{HCC}$ in vitro experiments. The current study aimed to examine the expression of NOR1 mRNA and protein expression in specimens of normal liver, hepatitis, cirrhosis and HCC, together representing the process of HCC development. Furthermore, the association between NOR1 expression and clinicopathological parameters of HCC patients was analyzed. Tissue microarrays containing the specimens of human normal liver, hepatitis, cirrhosis and HCC were purchased, and in situ hybridization and immunohistochemistry were used to detect the expression of NOR1 mRNA and protein expression, respectively. It was revealed that the positive rate of NOR 1 protein and mRNA expression in the specimens of hepatitis and cirrhosis were not significantly different from that in the normal liver samples. However, the specimens of HCC exhibited an increased positive rate of NOR1 protein and mRNA expression in comparison with the normal liver samples. In addition, a higher positive rate of NOR1 protein expression was observed in HCC patients with a poor pathological
\end{abstract}

Correspondence to: Dr Ming Qiu, Department of Laboratory Medicine, Xiangya Medical School, Central South University, 138 Tongzipo Road, Changsha, Hunan 410013, P.R. China

E-mail: qiu_ming@yeah.net

Dr Xin-Min Nie, Clinical Laboratory Centre of The Third Xiangya Hospital, Central South University, 138 Tongzipo Road, Changsha, Hunan 410013, P.R. China

E-mail: niexm6918@163.com

Key words: oxidored-nitro domain-containing protein 1, hepatocellular carcinoma, hepatitis, cirrhosis, clinicopathological parameters differentiation grade and high tumor node metastasis (TNM) stage. In conclusion, the present study provides evidence, for the first time, of the increased expression of NOR1 in human HCC tissues, and its correlation with the pathological stage and TNM status. These findings indicate that NOR1 may be involved in the progression of HCC and it could be employed as a predictive biomarker in HCC development.

\section{Introduction}

Hepatocellular carcinoma (HCC) accounts for $85-90 \%$ cases of primary liver cancer (1). It is the fifth most common malignancy and the third leading cause of cancer-related mortality worldwide (1-3). The epidemiological characteristics of liver cancer differ between various countries; for example, $\sim 85 \%$ of cases of liver cancer occur in developing countries and $54 \%$ occur in China (4). Furthermore, $>80 \%$ of patients with HCC have a history of hepatitis or cirrhosis, and HCC generally has a poor prognosis $(1,5-7)$. The majority of patients with $\mathrm{HCC}$ are present and are diagnosed in the advanced stages of the disease (5), and no effective chemotherapy or radiotherapy exists for the advanced disease. Surgical resection is effective only in the early stages of HCC, however, the 5-year survival rate is as low as $25-39 \%$ following surgery (8). It has been demonstrated that multiple genes are altered during the process of hepatocarcinogenesis (9). Understanding the molecular mechanisms that induce hepatocarcinogenesis may improve the screening, prevention and treatment of patients with HCC (10).

Oxidored-nitro domain-containing protein 1 (NOR1) gene is a nitroreductase (NTR) gene that was initially isolated from nasopharyngeal carcinoma (NPC) (11). The NOR1 gene encodes two transcripts and acts as a candidate tumor repressor gene associated with NPC. It has a similar activity to bacterial NTR, which converts 5-(aziridin-1-yl)-2,4-dinitrobenzamide (CB1954), a monofunctional alkylating agent, into a toxic form. A previous study supported the hypothesis that NOR1 is involved in the chemical carcinogenesis of hepatic cancer. NOR1 overexpression increased the expression levels of growth factor receptor-bound protein 2 (Grb2) mRNA and protein in HepG2 cells, and activated mitogen-activated protein kinase (MAPK) signal transduction, thus leading to enhanced CB1954-induced cell killing in HepG2 cells (12). 
Furthermore, DNA microarray data suggested that overexpression of NOR1 protein results in altered gene expression profiles in HepG2 cells, including 59 upregulated genes and 103 downregulated genes (13). These findings indicate that the NOR1 gene may have an important role in the development of HCC.

The present study examined, for the first time, the expression levels of NOR1 mRNA and protein in specimens of human normal liver, hepatitis, cirrhosis and HCC, together representing the process of $\mathrm{HCC}$ development. In addition, the association, between NOR1 expression and clinicopathological parameters of HCC patients was investigated. The present study may facilitate in elucidating the role of NOR1 expression in liver carcinogenesis. The study was approved by the Ethics Committee of The Third Xiangya Hospital, Central South University (Changsha, Hunan, China).

\section{Materials and methods}

Tissue microarrays. Sections $(5 \mu \mathrm{m})$ of formalin-fixed, paraffin-embedded tissue microarrays (cat. no. LV20812) were purchased from US Biomax, Inc. (Rockville, MD, USA). The tissue microarray contained 16 samples of normal human liver, 24 samples of hepatitis, 32 samples of cirrhosis and 32 samples of HCC. Sections were arranged in duplicate cores per sample.

In situ hybridization (ISH). The formalin-fixed paraffin-embedded sections were baked at $60^{\circ} \mathrm{C}$ for $30 \mathrm{~min}$, then deparaffinized by immersing in xylene (Sinopharm Chemical Reagent Co., Ltd., Shanghai, China) for $15 \mathrm{~min}$ twice. After immersing in 100\% ethanol (Sinopharm Chemical Reagent Co., Ltd.) for $5 \mathrm{~min}$, the slides were air-dried and then incubated with pepsin (Coolaber Technology Co., Ltd., Beijing, China) at $37^{\circ} \mathrm{C}$ for $30 \mathrm{~min}$. Digoxigenin-labeled RNA probes were synthesized by Sangon Biotech Co., Ltd. (Shanghai, China). The sequences were as follows: 5'-CTAAGTTCTTTGATGATCCAGACA CATGAGTTTCCACAGGCTGATTCACGCT-3'dig. The probes were diluted in prewarmed hybridization buffer (Wuhan Boster Biological Tehnology Ltd.., Wuhan, Hubei, China) to a concentration of $10 \mathrm{ng} / \mu \mathrm{l}$ and added to the slides for incubation at $37^{\circ} \mathrm{C}$ overnight. The slides were washed with saline-sodium citrate and Tris-buffered saline (both Coolaber Technology Co., Ltd.,), then incubated with mouse anti-digoxygenin monoclonal antibody (1:200 dilution; cat. no. ab119345; Abcam, Cambridge, MA, USA) at $4^{\circ} \mathrm{C}$ overnight. For signal development, nitroblue tetrazolium and bromochloroindolyl phosphate were used for staining at $37^{\circ} \mathrm{C}$ for $30 \mathrm{~min}$, and nuclear fast red dye served as the counterstain at $37^{\circ} \mathrm{C}$ for $1-2$ min (all Sigma-Aldrich, St. Louis, MO, USA).

Immunohistochemistry (IHC). The sections were baked at $60^{\circ} \mathrm{C}$ for $30 \mathrm{~min}$ followed by deparaffinization in xylene and rehydrated with graded ethanol. Antigen retrieval was performed by heating the sections in $0.01 \mathrm{M}$ citrate buffer (Coolaber Technology Co., Ltd.) for 2 min, then adding 3\% $\mathrm{H}_{2} \mathrm{O}_{2}$ /methanol solution (Sinopharm Chemical Reagent Co., Ltd.) to quench endogenous peroxidase. The sections were subsequently incubated with goat anti-NOR1 polyclonal antibody (1:50 dilution; cat. no. sc-161980; Santa Cruz Biotechnology, Inc., Santa Cruz, CA, USA) at $4^{\circ} \mathrm{C}$ overnight. After washing with $0.1 \%$ Tween-20/phosphate-buffered saline (Coolaber Technology Co., Ltd.), Polymer Helper (ZSGB-BIO, Beijing, China) was added to the sections and incubated at room temperature for $15 \mathrm{~min}$. The sections were washed for three times and then incubated with horseradish peroxidase-conjugated anti-goat IgG (1:2,000 dilution; cat. no. PV-9003; ZSGB-BIO) at room temperature for $15 \mathrm{~min}$. The slides were stained using a DAB staining kit (Fuzhou Maixin Biotech Co., Ltd., Fuzhou, China) and counterstained with hematoxylin (Beyotime Institute of Biotechnology, Shanghai, China) at $37^{\circ} \mathrm{C}$ for 3-5 $\mathrm{min}$.

Scoring method. The present study used the same semiquantitative scoring method for ISH and IHC $(14,15)$. The sections were semiquantitatively analyzed independently by two pathologists. All staining was observed using an E200 microscope (Nikon, Tokyo, Japan). The staining intensity was scored as 0 (negative), 1 (weak), 2 (moderate) or 3 (strong). The staining density score was based on the percentage of positive cells, as follows: $0(0 \%), 1(1-10 \%)$, $2(11-50 \%), 3(51-80 \%)$ and $4(81-100 \%)$. The staining intensity and density scores were multiplied and used as the overall score. An overall score of $>3$ was considered to indicate positive NOR1 expression; scores of $\leq 3$ indicated negative NOR1 expression.

Statistical analysis. Statistical analysis was performed using SPSS software (version 19.0; IBM SPSS, Chicago, IL, USA). Data are representative of at least three independent experiments. Pearson's $\chi^{2}$ test and Fishers exact test were performed to compare differences between groups. $\mathrm{P}<0.05$ was considered to indicate a statistically significant.

\section{Results}

Expression of NOR1 mRNA expression in normal liver, hepatitis, cirrhosis and HCC tissues. NOR1 mRNA ISH was performed on all sections representing human normal liver, hepatitis, cirrhosis and HCC. Representative staining patterns for NOR1 mRNA are indicated in Fig. 1. Positive signals were detected in the cytoplasm and/or nucleus. Table I indicates the expression of NOR1 mRNA in normal liver, hepatitis, cirrhosis and HCC. The positive rate of NOR1 mRNA expression in normal liver, hepatitis and cirrhosis was $43.8,58.3$ and $65.6 \%$, respectively. The expression of NOR1 mRNA in hepatitis and cirrhosis did not appear to be significantly different from the normal liver $(\mathrm{P}>0.05)$. By contrast, positive expression of NOR1 mRNA was exhibited in $25(78.1 \%) \mathrm{HCC}$ cases and negative expression of NOR1 mRNA was observed in the remaining 7 cases (21.9\%). The positive rate of NOR1 mRNA in patients with HCC was significantly higher compared with the normal control $(\mathrm{P}=0.017)$.

Expression of NOR1 protein expression normal liver, hepatitis, cirrhosis and HCC tissues. IHC was performed to examine the expression of NOR1 protein in human normal 
Table I. Expression of NOR1 mRNA in normal liver, hepatitis, cirrhosis and HCC.

\begin{tabular}{|c|c|c|c|c|c|}
\hline \multirow[b]{2}{*}{ Specimen type } & \multirow[b]{2}{*}{$\mathrm{n}$} & \multicolumn{2}{|c|}{ NOR1 mRNA expression, n (\%) } & \multirow[b]{2}{*}{$\chi^{2}$} & \multirow[b]{2}{*}{ P-value ${ }^{\mathrm{a}}$} \\
\hline & & Negative & Positive & & \\
\hline Normal & 16 & $9(56.2)$ & 7 (43.8) & & \\
\hline Hepatitis & 24 & $10(41.7)$ & $14(58.3)$ & 0.819 & 0.366 \\
\hline Cirrhosis & 32 & $11(34.4)$ & $21(65.6)$ & 2.100 & 0.147 \\
\hline $\mathrm{HCC}$ & 32 & 7 (21.9) & $25(78.1)$ & 5.672 & 0.017 \\
\hline
\end{tabular}

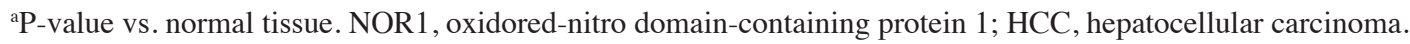

Table II. Expression of NOR1 protein in normal liver, hepatitis, cirrhosis and HCC.

\begin{tabular}{|c|c|c|c|c|c|}
\hline \multirow[b]{2}{*}{ Specimen type } & \multirow[b]{2}{*}{$\mathrm{n}$} & \multicolumn{2}{|c|}{ NOR1 protein expression, $\mathrm{n}(\%)$} & \multirow[b]{2}{*}{$\chi^{2}$} & \multirow[b]{2}{*}{ P-value ${ }^{a}$} \\
\hline & & Negative & Positive & & \\
\hline Normal & 16 & $16(100.0)$ & $0(0.0)$ & & \\
\hline Hepatitis & 24 & $21(87.5)$ & $3(12.5)$ & 2.162 & 0.141 \\
\hline Cirrhosis & 32 & $27(84.4)$ & $5(15.6)$ & 2.791 & 0.095 \\
\hline $\mathrm{HCC}$ & 32 & $11(34.4)$ & $21(65.6)$ & 18.667 & $<0.001$ \\
\hline
\end{tabular}

aP-value vs. normal tissue. NOR1, oxidored-nitro domain-containing protein 1; HCC, hepatocellular carcinoma.
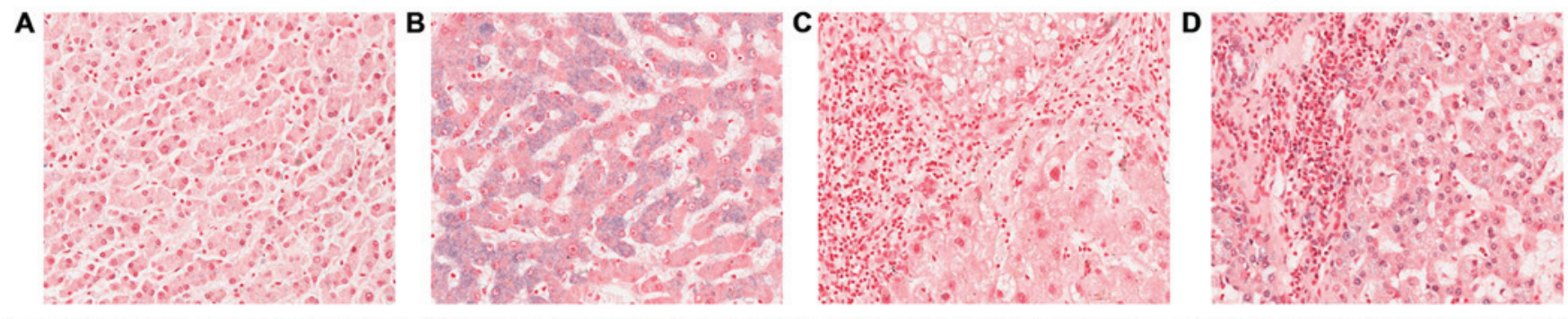

E
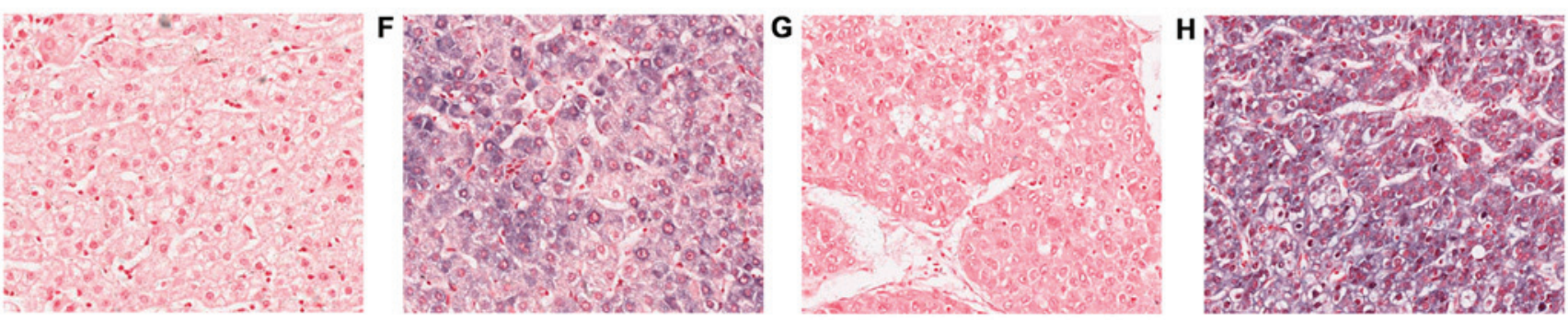

Figure 1. Expression of oxidored-nitro domain-containing protein 1 (NOR1) mRNA in normal liver, hepatitis, cirrhosis and HCC. (A) Negative and (B) positive expression of NOR1 mRNA in normal liver. (C) Negative and (D) positive expression of NOR1 mRNA in hepatitis. (E) Negative and (F) positive expression of NOR1 mRNA in cirrhosis. (G) Negative and (H) positive expression of NOR1 mRNA in hepatocellular carcinoma. Nitroblue tetrazolium, bromochloroindolyl phosphate and nuclear fast red staining; magnification, $\mathrm{x} 400$.

liver, hepatitis, cirrhosis and HCC. Fig. 2 shows representative staining patterns of NOR1 protein. The results indicated that NOR1 protein was expressed at variable levels, and localized within the cellular nuclei and cytoplasm.

Negative expression for NOR1 protein was observed in all normal liver samples, while the positive rate was $12.5 \%$ in hepatitis and $15.6 \%$ in cirrhotic liver samples. However, no significant difference in positive expression rate was observed between normal liver and hepatitis/cirrhotic liver samples $(\mathrm{P}>0.05)$.

NOR1 protein was expressed differentially between the normal liver and HCC. In a total of 32 cases of HCC, the expression of NOR1 protein was positive in $21(65.6 \%)$ cases and negative $(34.4 \%)$ in the remaining 11 cases. The positive rate of NOR1 protein expression was significantly higher in HCC tissues compared with the normal liver tissues ( $\mathrm{P}<0.001$; Table II). 
Table III. Association between NOR1 mRNA expression and clinicopathological parameters of patients with HCC.

\begin{tabular}{|c|c|c|c|c|c|}
\hline \multirow[b]{2}{*}{ Feature } & \multirow[b]{2}{*}{$\mathrm{n}$} & \multicolumn{2}{|c|}{ NOR1 mRNA expression, n (\%) } & \multirow[b]{2}{*}{$\chi^{2}$} & \multirow[b]{2}{*}{ P-value } \\
\hline & & Negative & Positive & & \\
\hline \multicolumn{6}{|c|}{ Age, years } \\
\hline$<50$ & 15 & $4(57.1)$ & $11(44.0)$ & \multirow[t]{2}{*}{0.379} & \multirow[t]{2}{*}{0.678} \\
\hline$\geq 50$ & 17 & $3(42.9)$ & $14(56.0)$ & & \\
\hline \multicolumn{6}{|l|}{ Gender } \\
\hline Male & 24 & $4(57.1)$ & $20(80.0)$ & \multirow[t]{2}{*}{1.524} & \multirow[t]{2}{*}{0.327} \\
\hline Female & 8 & $3(42.9)$ & $5(20.0)$ & & \\
\hline \multicolumn{6}{|l|}{ HBsAg } \\
\hline$(+)$ & 16 & $3(27.3)$ & $13(61.9)$ & \multirow[t]{2}{*}{3.463} & \multirow[t]{2}{*}{0.135} \\
\hline$(-)$ & 16 & $8(72.7)$ & $8(38.1)$ & & \\
\hline \multicolumn{6}{|c|}{ Pathological stage } \\
\hline I & 3 & $2(28.6)$ & $1(4.0)$ & \multirow[t]{3}{*}{4.355} & \multirow[t]{3}{*}{0.113} \\
\hline II & 19 & $4(57.1)$ & $15(60.0)$ & & \\
\hline III & 10 & $1(14.3)$ & $9(36.0)$ & & \\
\hline \multicolumn{6}{|c|}{ TNM status } \\
\hline I & 2 & $1(14.3)$ & $1(4.0)$ & \multirow[t]{4}{*}{1.234} & \multirow[t]{4}{*}{0.745} \\
\hline II & 19 & $4(57.1)$ & $15(60.0)$ & & \\
\hline III & 10 & $2(28.6)$ & $8(32.0)$ & & \\
\hline IV & 1 & $0(0.0)$ & $1(4.0)$ & & \\
\hline
\end{tabular}

NOR1, oxidored-nitro domain-containing protein 1; HCC, hepatocellular carcinoma; TNM, tumor-node-metastasis.
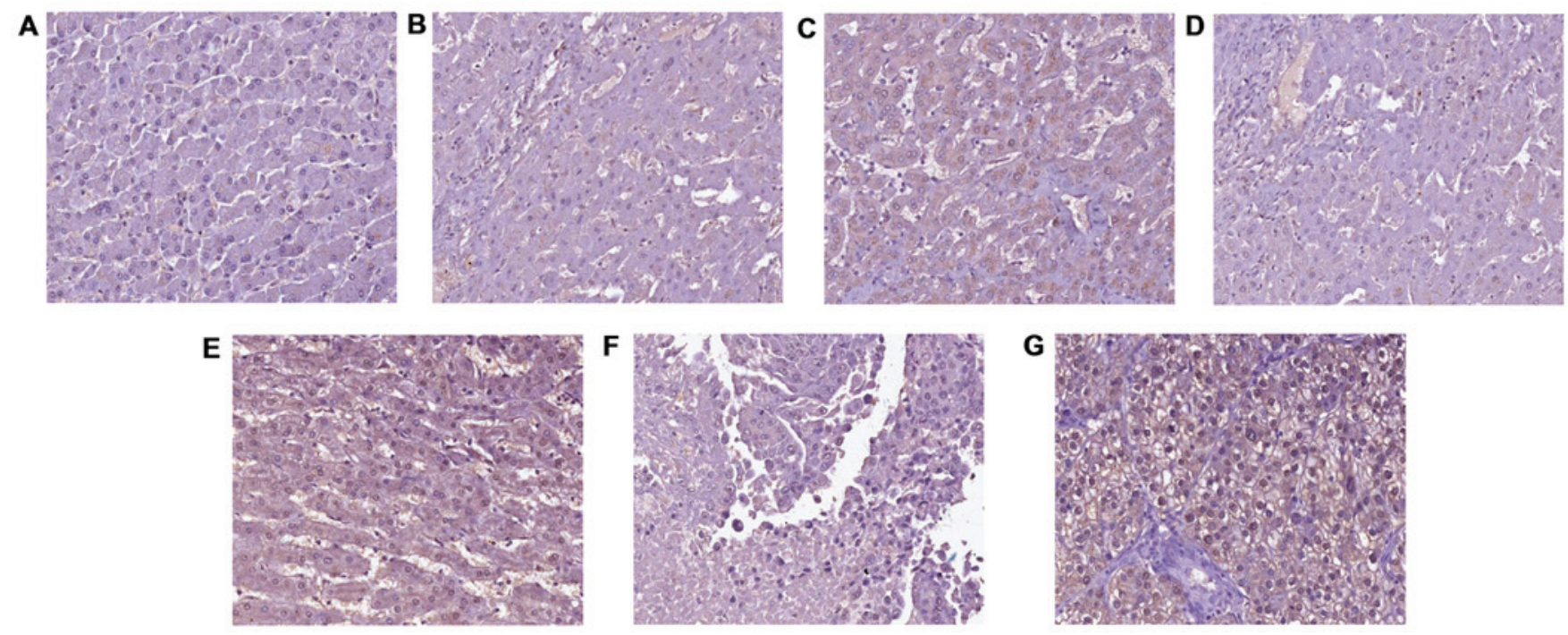

Figure 2. Expression of oxidored-nitro domain-containing protein 1 (NOR1) protein in normal liver, hepatitis, cirrhosis and HCC, as determined by immunohistochemistry. (A) Negative expression of NOR1 protein in normal liver. (B) Negative and (C) posiitve expression of NOR1 protein in hepatitis. (D) Negative and (E) positive expression of NOR1 protein in cirrhosis. (F) Negative and (G) positive expression of NOR1 protein in hepatocellular carcinoma. 3,3'-diaminobenzidine and hematoxylin.staining; magnification, $\mathrm{x} 400$.

Correlation between NOR1 expression and clinicopathological parameters of patients with HCC. The present study also analyzed the association between NOR1 expression and clinicopathological parameters of patients with HCC. The results in Table III indicate that there was no statistically significant association between NOR1 mRNA expression and any of the clinicopathological parameters investigated $(\mathrm{P}>0.05)$. However, Table IV demonstrates that NOR1 protein expression was correlated with the differentiation degree and tumor-node-metastasis (TNM) (16) tumor stage of patients with HCC. The NOR1 protein positive protein expression rate was significantly higher in HCC patients 
Table IV. Association between NOR1 protein expression and clinicopathological parameters of patients with HCC.

\begin{tabular}{|c|c|c|c|c|c|}
\hline \multirow[b]{2}{*}{ Feature } & \multirow[b]{2}{*}{$\mathrm{n}$} & \multicolumn{2}{|c|}{ NOR1 protein expression, $\mathrm{n}(\%)$} & \multirow[b]{2}{*}{$\chi^{2}$} & \multirow[b]{2}{*}{ P-value } \\
\hline & & Negative & Positive & & \\
\hline \multicolumn{6}{|c|}{ Age, years } \\
\hline$<50$ & 15 & $4(36.4)$ & $11(52.4)$ & \multirow[t]{2}{*}{0.744} & \multirow[t]{2}{*}{0.472} \\
\hline$\geq 50$ & 17 & 7 (63.6) & $10(47.6)$ & & \\
\hline \multicolumn{6}{|l|}{ Gender } \\
\hline Male & 24 & $6(54.5)$ & $18(85.7)$ & \multirow[t]{2}{*}{3.740} & \multirow[t]{2}{*}{0.088} \\
\hline Female & 8 & $5(45.5)$ & $3(14.3)$ & & \\
\hline \multicolumn{6}{|l|}{ HBsAg } \\
\hline$(+)$ & 16 & $4(57.1)$ & $12(48.0)$ & \multirow[t]{2}{*}{0.183} & \multirow[t]{2}{*}{1.000} \\
\hline$(-)$ & 16 & $3(42.9)$ & $13(52.0)$ & & \\
\hline \multicolumn{6}{|c|}{ Pathological stage } \\
\hline I & 3 & $3(27.3)$ & $0(0.0)$ & \multirow[t]{3}{*}{6.709} & \multirow[t]{3}{*}{0.035} \\
\hline II & 19 & $6(54.5)$ & $13(61.9)$ & & \\
\hline III & 10 & $2(18.2)$ & $8(38.1)$ & & \\
\hline \multicolumn{6}{|c|}{ TNM status } \\
\hline I & 2 & $2(18.2)$ & $0(0.0)$ & \multirow[t]{4}{*}{11.002} & \multirow[t]{4}{*}{0.012} \\
\hline II & 19 & $9(81.8)$ & $10(47.6)$ & & \\
\hline III & 10 & $0(0.0)$ & $10(47.6)$ & & \\
\hline IV & 1 & $0(0.0)$ & $1(4.8)$ & & \\
\hline
\end{tabular}

NOR1, oxidored-nitro domain-containing protein 1; HCC, hepatocellular carcinoma; TNM, tumor-node-metastasis.

with a low differentiation degree and a high TNM stage $(\mathrm{P}<0.05)$.

\section{Discussion}

The NOR1 gene was initially identified in NPC by Nie et al in 2003 (11). The expression of NOR1 was downregulated in the CNE1 NPC cell line in comparison to normal nasopharyngeal epithelial cells; however, enzymatic activity was higher in the CNE1 cells compared with the normal nasopharyngeal epithelial cells. NOR1 is regulated by heat shock factor 1 and nuclear respiratory factor 1 (17), which are two stress-responsive transcription factors that have important roles in carcinogenesis $(18,19)$. During the last decade, research regarding the association between NOR1 expression and human cancer has predominantly focused on NPC (20-22). It has been demonstrated that NOR1 is able to regulate NPC cell proliferation, apoptosis, autophagy and metabolism $(20,21)$. In addition, a small number of studies have reported that NOR1 overexpression is associated with prostate (23) and cervical (21) cancer.

Certain in vitro studies also suggest that NOR1 may be a candidate gene for hepatocarcinogenesis. NOR1 overexpression may induce Grb2 and E-selectin expression in HepG2 cells, and activate MAPK signal transduction $(12,13,24)$. These studies indicated that NOR1 may be important in the formation of chemical carcinogens and carcinogenesis of HCC.

The development of HCC is a multistep process with the involvement of a multifactorial etiology. It is well-established that HCC frequently arises in the setting of cirrhosis, and cirrhosis is attributable to chronic hepatitis $\mathrm{B}$ or $\mathrm{C}$ virus infection. This trend has been observed in cases in almost all countries (25-27).

In the current study, the expression of NOR1 was determined in specimens of normal liver, hepatitis, cirrhosis and HCC obtained as tissue array slides. ISH was used to detect the expression of NOR1 mRNA, whereas the expression of NOR1 protein was examined by IHC. The results indicated that NOR1 was primarily localized within the nuclei and cytoplasm.

By performing a western blot assay, Xiang et al identified that human livers exhibit an absence of NOR1 protein. Furthermore, tissue sections from the liver did not stain positive for NOR1 in an IHC assay (28). Consistent with the results in the literature, the IHC results of the present study demonstrated negative expression for NOR1 protein in all 16 normal liver specimens analyzed. However, the ISH assay revealed that the positive rate of NOR1 mRNA was $43.8 \%$ in normal liver specimens.

In a previous study by Xiang et al, the expression of human NOR1 protein expression was examined in various normal and cancerous tissues. It was observed that NOR1 expression was weak or negative in the majority of malignant cells, however, moderate to strong expression of NOR1 was displayed in liver cancer cells (29). Similarly, the present study identified a trend for increased positive rate of NOR1 protein and mRNA expression from normal liver samples to hepatitis, cirrhosis and HCC samples. However, positive NOR1 protein and mRNA expression observed in the normal liver samples was not significantly different to the hepatitis and cirrhotic liver samples. By contrast, 
the positive rate of NOR1 mRNA and protein expression in patients with $\mathrm{HCC}$ was significantly higher in comparison to the normal control. The aforementioned findings indicate a possible role of NOR1 in the progression of HCC. Furthermore, the current study identified that NOR1 protein expression correlates with certain clinicopathological parameters of HCC, including pathological stage and TNM status. The positive rate of NOR1 expression was higher in HCC patients with poor pathological differentiation grade and high TNM stage.

In conclusion, the present study examined the mRNA and protein expression of NOR1 in normal human liver, hepatitis, cirrhosis and HCC specimens, which together represent the process of HCC development. NOR1 expression was increased in HCC and its expression was correlated with clinicopathological parameters of patients with HCC. Thus, NOR1 may be involved in HCC progression and could be employed as a predictive biomarker in $\mathrm{HCC}$ development.

\section{Acknowledgements}

The present study was supported by the National Natural Science Foundation of China (grant nos. 30300383, 81072270 and 81101828) and the Fundamental Research Funds for the Central Universities (grant no. 2011JQ030).

\section{References}

1. El-Serag HB and Rudolph KL: Hepatocellular carcinoma: Epidemiology and molecular carcinogenesis. Gastroenterology 132: 2557-2576, 2007.

2. Altekruse SF, McGlynn KA and Reichman ME: Hepatocellular carcinoma incidence, mortality and survival trends in the United States from 1975 to 2005. J Clin Oncol 27: 1485-1491, 2009.

3. Parkin DM, Bray F, Ferlay J and Pisani P: Global cancer statistics, 2002. CA Cancer J Clin 55: 74-108, 2005.

4. Zhang W, Shu XO, Li H, Yang G, Cai H, Ji BT, Gao J, Gao YT, Zheng W and Xiang YB: Vitamin intake and liver cancer risk: A report from two cohort studies in China. J Natl Cancer Inst 104: 1173-1181, 2012.

5. Teo EK and Fock KM: Hepatocellular carcinoma: An Asian perspective. Dig Dis 19: 263-268, 2001.

6. Zhu AX: Systemic therapy of advanced hepatocellular carcinoma: How hopeful should we be? Oncologist 11: 790-800, 2006.

7. El-Serag HB and Mason AC: Rising incidence of hepatocellular carcinoma in the United States. N Engl J Med 340: 745-750, 1999.

8. Thomas MB and Zhu AX: Hepatocellular carcinoma: The need for progress. J Clin Oncol 23: 2892-2899, 2005.

9. Shiraha H, Yamamoto K and Namba M: Human hepatocyte carcinogenesis (review). Int J Oncol 42: 1133-1138, 2013.

10. Hagymási K and Tulassay Z: Epidemiology, risk factors and molecular pathogenesis of primary liver cancer. Orv Hetil 149: 541-548, 2008 (In Hungarian).

11. Nie X, Zhang B,Li X, Xiang J, Xiao B, Ma J,Zhou M, Zhu S, Lu H, Gui R, et al: Cloning, expression and mutation analysis of NOR1, a novel human gene down-regulated in HNE1 nasopharyngeal carcinoma cell line. J Cancer Res Clin Oncol 129: 410-414, 2003.

12. Gui R, Li D, Qi G, Suhad A and Nie X: Inhibition of Grb2-mediated activation of MAPK signal transduction suppresses NOR1/CB1954-induced cytotoxicity in the HepG2 cell line. Oncol Lett 4: 566-570, 2012.
13. Shen CM, Nie XM and Li DQ: Screening of genes differentially expressed in HepG2 cells transfected with NOR1 gene using DNA microarray. Practical Preventive Medicine 14: 609-611, 2007 (In Chinese).

14. Gu X, Fu M, Ding Y, Ni H, Zhang W, Zhu Y, Tang X, Xiong L, Li J, Qiu L, et al: TIMP-3 expression associates with malignant behaviors and predicts favorable survival in HCC. PLoS One 9: e106161, 2014.

15. Friedrichs K, Gluba S, Eidtmann $\mathrm{H}$ and Jonat W: Overexpression of p53 and prognosis in breast cancer. Cancer 72: 3641-3647, 1993.

16. Edge SB, Byrd DR, Compton CC, Fritz AG, Greene FL and Trotti A (eds): AJCC Cancer Staging Manual. 7th edition. Springer, New York, 2010.

17. Li W, Li X, Wang W, Li X, Tan Y, Yi M, Yang J, McCarthy JB, Xiong W, Wu M, et al: NOR1 is an HSF1- and NRF1-regulated putative tumor suppressor inactivated by promoter hypermethylation in nasopharyngeal carcinoma. Carcinogenesis 32: 1305-1314, 2011.

18. Xu Z, Chen L, Leung L, Yen TS, Lee C and Chan JY: Liver-specific inactivation of the Nrf1 gene in adult mouse leads to nonalcoholic steatohepatitis and hepatic neoplasia. Proc Natl Acad Sci USA 102: 4120-4125, 2005.

19. Dai C, Whitesell L, Rogers AB and Lindquist S: Heat shock factor 1 is a powerful multifaceted modifier of carcinogenesis. Cell 130: 1005-1018, 2007.

20. Li W, Li X, Wang W, Yi M, Zhou Y, Zheng P, Xiong W, Yang J, Peng S, McCarthy JB, et al: Tumor suppressor gene Oxidored-nitro domain-containing protein 1 regulates nasopharyngeal cancer cell autophagy, metabolism and apoptosis in vitro. Int J Biochem Cell Biol 45: 2016-2026, 2013.

21. Ouyang J, Wu M, Huang C, Cao L and Li G: Overexpression of oxidored-nitro domain containing protein 1 inhibits human nasopharyngeal carcinoma and cervical cancer cell proliferation and induces apoptosis: Involvement of mitochondrial apoptotic pathways. Oncol Rep 29: 79-86, 2013.

22. Wang W, Li X, Zhang W, Li W, Yi M, Yang J, Zeng Z, Colvin Wanshura LE, McCarthy JB, Fan S, et al: Oxidored-nitro domain containing protein 1 (NOR1) expression suppresses slug/vimentin but not snail in nasopharyngeal carcinoma: Inhibition of EMT in vitro and in vivo in mice. Cancer Lett 348: 109-118, 2014.

23. Shan Z, Hou Q, Zhang N, Guo L, Zhang X, Ma Y and Zhou Y: Overexpression of oxidored-nitro domain containing protein 1 induces growth inhibition and apoptosis in human prostate cancer PC3 cells. Oncol Rep 32: 1939-1946, 2014.

24. Li YJ, Wang WW and Li DQ: Effect of NOR1 Gene on Level of E-selectin in HepG2 Cells and its Mechanism. The Practical Journal of Cancer 25: 9-12, 2010 (In Chinese).

25. Perz JF, Armstrong GL, Farrington LA, Hutin YJ and Bell BP: The contributions of hepatitis B virus and hepatitis $C$ virus infections to cirrhosis and primary liver cancer worldwide. J Hepatol 45: 529-538, 2006.

26. Davila JA, Morgan RO, Shaib Y, McGlynn KA and El-Serag HB: Hepatitis $\mathrm{C}$ infection and the increasing incidence of hepatocellular carcinoma: A population-based study. Gastroenterology 127: 1372-1380, 2004.

27. Kanwal F, Hoang T, Kramer JR, Asch SM, Goetz MB, Zeringue A, Richardson P and El-Serag HB: Increasing prevalence of HCC and cirrhosis in patients with chronic hepatitis $\mathrm{C}$ virus infection. Gastroenterology 140: 1182-1188, 2011.

28. Xiang B, Wang W, Li W, Li X, Li X and Li G: Differential expression of oxidored nitro domain containing protein 1 (NOR1), in mouse tissues and in normal and cancerous human tissues. Gene 493: 18-26, 2012.

29. Xiang B, Yi M, Wang L, Liu W, Zhang W, Ouyang J, Peng Y, Li W, Yin D, Zhou M, et al: Preparation of polyclonal antibody specific for NOR1 and detection of its expression pattern in human tissues and nasopharyngeal carcinoma. Acta Biochim Biophys Sin (Shanghai) 41: 754-762, 2009. 